\title{
Input output accounting systems in the European community - an appraisal of their usefulness in raising awareness of environmental problems
}

\author{
G. Goodlass ${ }^{\mathrm{a}, *}$, N. Halberg ${ }^{\mathrm{b}}$, G. Verschuur ${ }^{\mathrm{c}}$ \\ a ADAS High Mowthorpe, Duggleby, Malton, North Yorkshire YO17 8BP, UK \\ ${ }^{\mathrm{b}}$ DIAS, Department of Agricultural Systems, Research Centre Foulum, PO Box 50, DK-8830 Tjele, Denmark \\ ${ }^{\mathrm{c}}$ CLM, PO Box 10015, 3505 AA Utrecht, Netherlands
}

\section{Abstract}

Input Output Accounting systems (IOAs) can be used to identify farming practices which are not 'environmentally neutral' and thus unlikely to be sustainable in the long term. In an EU sponsored project, European countries were surveyed and over 50 farm level IOAs identified. The subjects covered by the IOAs included nutrients, pesticides, energy, soil/habitat, conservation, wastes (e.g. packaging and tyres) and other items such as veterinary products. Nearly half the IOAs covered more than one subject and nutrient budgets were the most commonly included ( $91 \%$ of the IOAs studied). Looking at the 30 single subject systems, most (26) were nutrients with only three pesticide and one energy based system. In total 50 systems covered nutrients. Overall, where specified, nutrient budgets covered nitrogen $(\mathrm{N})$, phosphorus (P) and potassium (K) in 13 cases, $\mathrm{N}$ and $\mathrm{P}$ in 12 cases, $\mathrm{N}$ only in nine and $\mathrm{P}$ only in four cases. The most common indicators for nutrient budgets were calculation of a balance followed by nitrate leached. The method by which indicators were evaluated and presented to farmers varied. Farming sectors were not equally represented with systems for the arable, dairy and pig sectors the most common. Farmers received a detailed interpretation of their results in two thirds of the systems, most commonly related to official limits or targets. Most of the systems were developed to reduce adverse environmental impacts and $65 \%$ of the systems were considered by the respondents to have had a positive environmental impact by reducing surpluses or improving waste disposal. Use of five of the systems could lead to a marketing advantage via certified produce with a recognised quality label. Where factual evidence as to effectiveness was available, the benefits varied between subject types (nutrients, energy and pesticides) and between sectors. Farmers' responses to the systems were generally positive and they appear to be a useful way of raising awareness of environmental problems. However, economic issues need to be considered, if the costs to the farmer outweigh the benefits, uptake will not be sustained. The type and nature of the interpretation is also important as the most successful IOAs in terms of continued use and interest appeared to be those where there was regular technical input from an adviser. Overall IOAs could offer a useful tool for voluntary improvement in agri-environmental performance on topics that are not already strongly regulated. But more studies are needed to ensure that farmers in reality change their behaviour and to develop the use of reference values.

(C) 2003 Elsevier B.V. All rights reserved.

Keywords: Inputs; Outputs; Nutrient balances; Environment; Indicators; Europe

\footnotetext{
* Corresponding author. Tel.: +44-1944-73-8646; fax: +44-1944-73-8434.

E-mail address: gillian.goodlass@adas.co.uk (G. Goodlass).
} 


\section{Introduction}

An important part of the food consumed in Europe is produced on intensive agricultural farms. The intensive nature of such systems means that food may often be produced at a relatively low price, but this may be at the expense of contributing to environmental pollution. The economic driving forces mean that intensive systems will continue in Europe. Therefore, it is necessary to tackle environmental problems of such systems by decreasing the pollution from for example nitrogen, phosphorus, pesticides and carbon dioxide.

Within any group of intensive farms there is a lot of variation in efficiency of production and often related to this is environmental performance (Langelaan, 1997). Adequate management information is an important pre-requisite to help farmers achieve higher efficiency and reduce environmental impacts. Management information can be given by Input Output Accounting systems (IOAs). Thus it is interesting to compare IOAs and analyse their role as a management instrument to improve efficiency and reduce environmental pollution. Although a variety of IOAs are already used across Europe, at the moment there is no complete overview of these systems, their scope, details and efficacy. Hence, the European Union (EU) Directorate General (DG agriculture and DG environment) authorised a comprehensive review and critical assessment of IOA experiences and the results are reported here.

\section{Materials and methods}

The study was split into three sections. In the first part a survey was carried out to identify as many IOAs as possible, in the second part a representative sub-selection was examined in more detail and for the third part an overall analysis of IOAs in terms of their indicators and effectiveness was carried out.

\subsection{Initial survey}

The IOAs of interest were defined as those in which inputs on farm were recorded and related to outputs, and which allowed an assessment of environmental performance and management change. As well as the EU countries the search covered the non EU countries of Norway, Switzerland and United States of America. A systematic search procedure was used which covered governments, farmers unions, research organisations, farm advisory services and other sources such as super market chains and product marketing organisations. A tick box questionnaire was sent to each contact person to collect information about design, content, management, monitoring and evaluation.

\subsection{Detailed survey}

Ten IOAs were selected for further study. They were chosen to represent a range of those systems which covered all three key subject areas (nutrients, pesticides and energy), together with one specialist system in each subject area and a mainly market based system. In general systems were chosen which had been in operation for some time and were reported to be effective and have good documentation. This survey was carried out by telephone contact with the systems co-ordinator and was based on a more elaborate questionnaire which probed for details about:

a) driving forces;

b) data collection, availability and calculations;

c) interpetation and use of results;

d) changes in the system;

e) effectiveness.

Comprehensive reports were made for each of the ten selected IOAs.

\subsection{Overall analysis}

An analysis of strengths and weaknesses of IOAs was carried out from two perspectives: the farmer and the societal/environmental evaluation of the used indicators and concepts. The analysis 
was limited to the information gathered on the systems in the study and focused on voluntary systems not linked specifically to mandatory agrienvironmental regulation (though some of the systems may be used as documentation of compliance with agri-environmental schemes or with product labelling). Thus, the focus of the study was not regulation measures but the efficacy of IOAs for motivating and facilitating farmers to increase their environmental performance. The analysis had a qualitative character in the cases where hard data were lacking.

\section{Results}

\subsection{Initial survey}

The questionnaire and accompanying letters were sent to 241 contact personnel in 204 different organisations as well as to a number of internal contacts in Centre for Agriculture and Environment (CLM) and Danish Institute of Agricultural Sciences (DIAS). A total of 55 completed questionnaires were received. Nearly half the systems covered more than one subject area. Most (91\%) of the 55 questionnaires covered the subject area of nutrients, whilst 38\% covered pesticides, 29\% energy and $44 \%$ other subjects including wastes. Looking at the 30 single subject systems, most (26) were nutrient with only three pesticide and one energy based system. A breakdown by industry sector is given in Table 1 .

The most common indicators for systems were nutrient balance $53 \%$, pesticide regime $27 \%$, energy balance $22 \%$ and nitrate leached $13 \%$. None of the other 19 indicators were used by more than three systems and eight were used by only one system. Where specified, nutrient balances covered nitrogen $(\mathrm{N})$, phosphorus $(\mathrm{P})$ and potassium $(\mathrm{K})$ in 13 cases, $\mathrm{N}$ and $\mathrm{P}$ in 12 cases, $\mathrm{N}$ only in nine and $\mathrm{P}$ only in four cases. Two systems also covered heavy metals, both of these were Danish.

The results are explained to farmers in a specific report (either written and/or verbal) in $65 \%$ of systems and in $40 \%$ of systems, farmers get information on the performance of other farmers using the system. The most common reference values for comparison and/or interpretation are official limits (49\%) followed by: own historic data $(38 \%)$, average values from a set of farms $(29 \%)$, experts view of best practice $(27 \%)$ and finally best results from a set of farms $(22 \%)$.

Farmers were compensated for the costs of joining in 17 of the systems. The effect of the system on farm income is shown in Table 2, overall there was a positive effect on income for about a third of the systems, notably the arable and dairy sectors. Use of five of the systems could lead to a marketing advantage via certified produce with a recognised quality label.

Respondents were asked to judge the effectiveness of their system in terms of its effect on input/ output balances and 43 replied. In 35 systems the respondents thought that its use had led to a reduction in the input/output ratio. There was no effect in five systems and in three systems the inputs were increased. Where quantified the range was from 0.5 to $90 \%$ reduction with the highest values occurring in systems, which included the horticultural protected crops sector. One respondent was able to differentiate between sectors and identified more benefits in the dairy sector than the arable and pig sectors, but most respondents did not differentiate between sectors.

\subsection{Detailed survey}

The aim of this analysis was to describe the chosen systems (Table 3) in detail and provide a factual comparison identifying any common reason between successful systems. Increasing con-

Table 1

Percentage of completed questionnaires covering each industry sector

\begin{tabular}{llllllll}
\hline Arable & Horticulture & Beef/veal & Dairy & Pigs & Poultry & Organic farming & Other (including protected crops) \\
\hline 76 & 53 & 45 & 62 & 56 & 44 & 49 & 31 \\
\hline
\end{tabular}


Table 2

Effect of system on farm income by sector (\%)

\begin{tabular}{llllllllll}
\hline & Arable & Horticulture & Beef/veal & Dairy & Pigs & Poultry & Organic farming & Other & All sectors \\
\hline Negative & 2 & 10 & 4 & 3 & 3 & 4 & 0 & 10 & 4 \\
No effect & 17 & 28 & 20 & 15 & 16 & 21 & 25 & 40 & 21 \\
Positive & 48 & 24 & 32 & 41 & 35 & 21 & 33 & 20 & 34 \\
Not known & 33 & 38 & 44 & 41 & 45 & 54 & 42 & 30 & 41 \\
\hline
\end{tabular}

cern about environmental issues was the driving force behind development of each of the systems studied. In most cases a major part of the funding to develop the system or run pilot projects came from government. The information required for the nutrient accounts is compared in Table 4. Some systems did not require all the information for each sector. All the nutrient systems gave farmers a specific explanation and this was usually in a written report. Comparisons with the farmers own historic data or average farm values were the most common. Only ethical accounts for livestock farms (EALF) and agro-ecological indicators (AI) had any information on reproducibility or variation of results between seasons.

Effects on farm income were variable both between sectors (e.g. AI) and between seasons (e.g. FHL). Benefits in terms of increased awareness of problem areas were identified by several respondents. Anecdotal evidence suggests that farmers are encouraged to make actual changes to their management on the basis of the systems, if they receive detailed help from an adviser asso- ciated with the system, or if the system results in a marketing advantage. It seems likely that IOAs could be used to increase awareness and provide evidence of the impact of management changes, they may need to be linked to supporting systems of technical advice.

\subsection{Overall analysis}

The range of indicators for nitrogen are shown in Table 5. Most IOAs use nutrient balances based on account data but very little information exists regarding how the indicator values (the size of the surplus on a given farm) were actually evaluated. Often the actual fertiliser use was compared with standard fertiliser requirements which automatically included a reference value. In one system (Eco-rating in Table 5) this result was further transformed using factors indicating risks of $\mathrm{N}$ losses and scaled into an 'Eco-rating' so that the farmer received a value between -100 and +100 for his nutrient management. Thus, the indicator was mix of account information regarding input

Table 3

Systems used in the detailed survey

\begin{tabular}{lllll}
\hline ID & Name & Country of origin & Countries used by & Subject \\
\hline GA & Green accounts & Denmark & Denmark & Nutrients (NPK) pesticides energy \\
EALF & Ethical account for livestock farms & Denmark & Denmark & Nutrients (NP) pesticides energy \\
EMA & Environmental management for agriculture & UK & World-wide & Nutrients (NPK) pesticides energy \\
AI & Agro-ecological indicators & France & France +Germany & Nutrients (NP) pesticides energy \\
AEL & Agricultural environment label & Netherlands & Netherlands & Nutrients (NP) pesticides energy \\
REPRO & Repro & Germany & Germany & Nutrients (NPK) pesticides energy \\
FHL & FHL-herdbooks system & Luxemburg & Luxemburg + Belgium & Nutrients (NPK) energy \\
STANK & STANK-farm level nutrient balance & Sweden & Sweden & Nutrients (NPK) \\
EYP & Environmental yardstick for pesticides & Netherlands & Netherlands + Bel- & Pesticides \\
& & & gium & Energy \\
EY & Energy yardstick & Netherlands & Netherlands & \\
\hline
\end{tabular}


Table 4

Data requirements for nutrient accounting (x, essential; o, optional)

\begin{tabular}{|c|c|c|c|c|c|c|c|c|}
\hline & GA & EALF & EMA & AI & AEL & REPRO & FHL & STANK \\
\hline \multicolumn{9}{|c|}{ Management information } \\
\hline Fertiliser use & $\mathrm{x}$ & $\mathrm{x}$ & $\mathrm{x}$ & $\mathrm{x}$ & $\mathrm{x}$ & $\mathrm{x}$ & $\mathrm{x}$ & $\mathrm{x}$ \\
\hline Manure use & $\mathrm{x}$ & $\mathrm{x}$ & $\mathrm{x}$ & $\mathrm{x}$ & $\mathrm{x}$ & & $\mathrm{x}$ & $\mathrm{x}$ \\
\hline Livestock & $\mathrm{x}$ & $\mathrm{x}$ & $\mathrm{x}$ & & $\mathrm{x}$ & $\mathrm{x}$ & $\mathrm{x}$ & $\mathrm{x}$ \\
\hline Feedstuff & $\mathrm{x}$ & $\mathrm{x}$ & $\mathrm{x}$ & & $\mathrm{x}$ & & $\mathrm{x}$ & $\mathrm{x}$ \\
\hline Seed & $\mathrm{x}$ & $\mathrm{x}$ & & & & $\mathrm{x}$ & $\mathrm{x}$ & $\mathrm{x}$ \\
\hline Milk & $\mathrm{x}$ & $\mathrm{x}$ & & & $\mathrm{x}$ & & $\mathrm{x}$ & $\mathrm{x}$ \\
\hline Eggs & & & & & & & $\mathrm{x}$ & $\mathrm{x}$ \\
\hline Crop types & $\mathrm{x}$ & $\mathrm{x}$ & $\mathrm{x}$ & $\mathrm{x}$ & $\mathrm{x}$ & $\mathrm{x}$ & o & $\mathrm{x}$ \\
\hline Soil type/analysis & & & $\mathrm{x}$ & $\mathrm{x}$ & $\mathrm{x}$ & o & o & $\mathrm{x}$ \\
\hline Irrigation/water use & $\mathrm{x}$ & $\mathrm{x}$ & $\mathrm{x}$ & $\mathrm{x}$ & $\mathrm{x}$ & & $\mathrm{x}$ & \\
\hline Rainfall & & & $\mathrm{x}$ & $\mathrm{x}$ & & o & & \\
\hline Machinery use & & $\mathrm{x}$ & $\mathrm{x}$ & $\mathrm{x}$ & & o & $\mathrm{x}$ & \\
\hline Farm or field size & $\mathrm{x}$ & $\mathrm{x}$ & $\mathrm{x}$ & $\mathrm{x}$ & $\mathrm{x}$ & & & $\mathrm{x}$ \\
\hline Economics & & & & & & o & & \\
\hline \multicolumn{9}{|l|}{ Nutrient specific } \\
\hline Nitrogen & $\mathrm{x}$ & $\mathrm{x}$ & $\mathrm{x}$ & $\mathrm{x}$ & $\mathrm{x}$ & $\mathrm{x}$ & $\mathrm{x}$ & $\mathrm{x}$ \\
\hline Phosphate & $\mathrm{x}$ & $\mathrm{x}$ & $\mathrm{x}$ & $\mathrm{x}$ & $\mathrm{x}$ & $\mathrm{x}$ & $\mathrm{x}$ & $\mathrm{x}$ \\
\hline Potash & $\mathrm{x}$ & & $\mathrm{x}$ & & & $\mathrm{x}$ & $\mathrm{x}$ & $\mathrm{x}$ \\
\hline Other nutrient & $\mathrm{x}$ & $\mathrm{x}$ & & & & & & \\
\hline Deposition & $\mathrm{x}$ & $\mathrm{x}$ & & & $\mathrm{x}$ & & & $\mathrm{x}$ \\
\hline $\mathrm{N}$ fixation & $\mathrm{x}$ & $\mathrm{x}$ & & & $\mathrm{x}$ & & & $\mathrm{x}$ \\
\hline Soil N supply & & & o & $\mathrm{x}$ & $\mathrm{x}$ & & & \\
\hline Mineralisation & & & & $\mathrm{x}$ & & & & \\
\hline Gaseous losses & & & $\mathrm{x}$ & $\mathrm{x}$ & & $\mathrm{x}$ & & $\mathrm{x}$ \\
\hline Drainage losses & & & $\mathrm{x}$ & $\mathrm{x}$ & & $\mathrm{x}$ & & \\
\hline Soil surface balance & & & & & & & & $\mathrm{x}$ \\
\hline Farm gate balance & $\mathrm{x}$ & $\mathrm{x}$ & $\mathrm{x}$ & & & & $\mathrm{x}$ & \\
\hline
\end{tabular}

and assumptions regarding output. A similar approach was developed in a second system (emission risk in Table 5) but here the modelled loss of $\mathrm{N}$ (in combination with evaluation of the farmers efforts to reduce losses) was used as the basis for transformation into the $0-10$ point scale.

Only limited documentation exists concerning the farmers view on the systems. Farmers found the concept of nutrient balances to be new and to provide information that could be acted upon. In general, most of the farmers replied that they had changed their management due to the systems. Unfortunately no information was available concerning farmers view on the two systems using the scaled ratings (EMA and $\mathrm{AI}$ ). In theory the scale makes comprehension of the results easier but the lack of inter-farm comparisons is a disadvantage as farmers have shown a strong appreciation of this facility in other systems.
From a societal/environmentalist point of view the effectiveness of IOAs can be defined as the degree to which farmers are supported in exploiting the possibilities for environmental improvement at low or no costs and beyond the limit regulated by existing public law and regulation. Effectiveness is then a combination of:

- the systems uptake in number of farmers;

- the degree to which farmers using them increase their awareness of environmental issues;

- the degree to which they make changes on their farms.

In this study IOA indicators were shown to increase awareness and change attitudes. Experiences from many of the pilot systems showed that farmers generally understood the indicators, were interested and that many of them had changed 


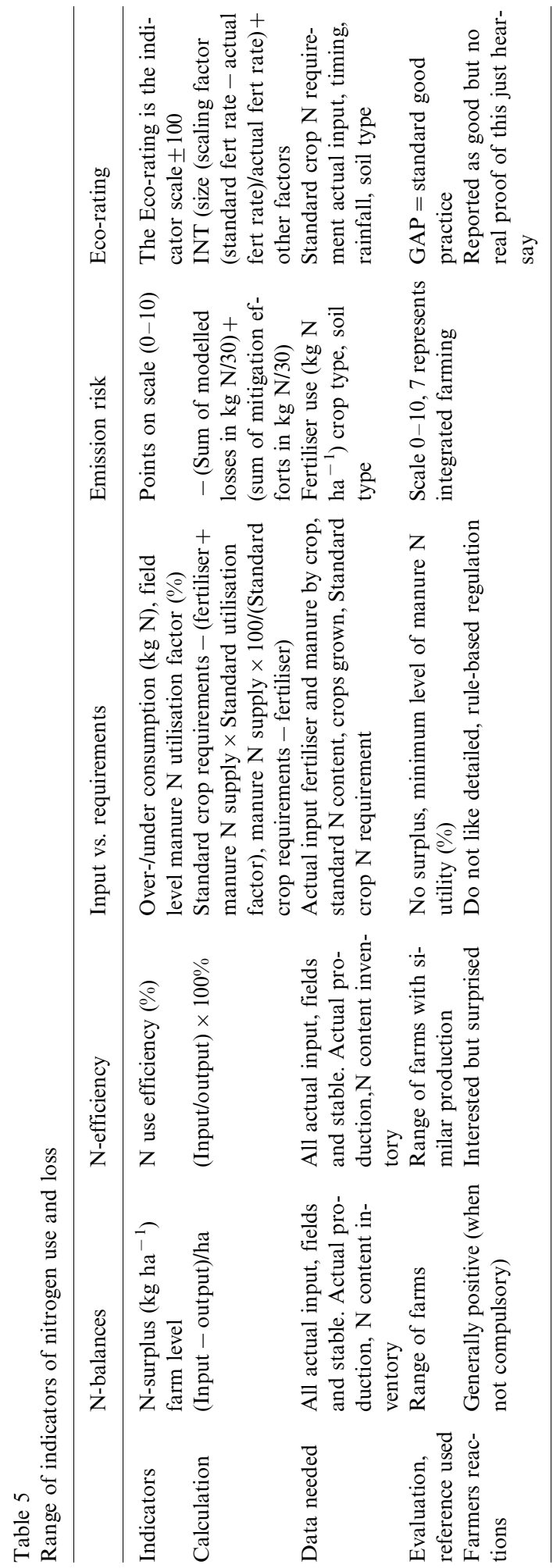

their management. One benefit of IOAs is probably that it makes it legitimate for advisors to address environmental issues while also discussing production economics. This may be one of the reasons why only systems linked to existing advisory services seem to make it beyond the pilot phase.

Among the 55 systems reviewed, 35 reported that the participating farmers had improved their environmental performance. In the detailed review documented evidence on specific farms was only available for five systems. The lack of information should not necessarily be interpreted as a lack of effect, but the fact that it is very difficult to prove the relationship between the use of such systems and the environmental performance of private farms.

\section{Discussion}

The 55 IOAs represented very different approaches although each had been developed and applied on farms in European countries with the aim of improving environmental performance. Major differences occurred in two characteristics: the number of topics covered (single or multiple) and the way indicators were presented. In many systems the indicators used were presented as calculations of input related to output and were derived from actual farm accounts data. Other systems present indicators that are transformed to a standard scale and often these indicators were based on a combination of practise and farm account data compared with norms for good agricultural practices (GAP). Scaled indicators are reported to promote clearer understanding by farmers (Lewis and Bardon, 1998) but this study provided no supporting evidence for this. The amount of information required to run the systems varied considerably even between systems which were ostensibly using the same indicators. Some systems split into 'sub-systems' which had different data requirements based on sector. Those systems which dealt with only one subject tended to go into greater detail than those which covered several sectors or subjects. Indicators which are too demanding in terms of data availability may not 
be practical in regions where farmers do not need to keep detailed accounts of input use or production levels for taxation or other purposes. If IOAs are to be used in Europe a more uniform and coherent concept for balances is needed. At a farm and herd level this has been discussed by Sveinsson et al. (1998), and at a national level by Hansen (2000).

The systems also differed in their origin and driving force. Only a few systems had been developed for mandatory use or for labelling and formal auditing. Most systems had been developed for the use by advisory services on a voluntary basis. A number of very different systems seem to have been successful. Effectiveness is defined here as the combination of a system with high (potential) impact on the participating farmers in combination with high uptake in terms of the number of farmers willing to use the system. The most successful appeared to be those where there was detailed/regular personal discussion of results with an adviser. Others (O'hlmér, 1998; Noe and Halberg, 1999) have reported that farmers' attitude to quantitative information as a means of management may be important.

Generally documentation of effects and uptake was poor and more investigations into this are needed. Many systems had not passed the pilot phase, but still achieved a positive evaluation by the farmers. In several examples the effort of researchers to develop a scientifically valid concept was not matched by efforts to secure the uptake by advisors or other institutions afterwards. The right institutional setting and political context seems to be more important than the character of the indicators used in terms of farmer uptake. But that does not mean that the choice of indicators is not important. In none of the reviewed systems were the use of confidence intervals or variation coefficients an established part of the procedure. Only few reports exist that analyse the variation between farms or between years on specific farms in order to decide to which degree differences are due to systematically different management practices. This is a limitation which needs to be addressed (Halberg, 1999). More studies are needed to ensure that farmers in reality change their behaviour and to develop the use of reference values.

\section{Conclusion}

IOAs operating in different Member States vary considerably in their emphasis and the breadth of their remit. This depends partly on the nature of the forces driving their establishment. The Common Agricultural Policy already provides a considerable number of instruments seeking to improve or maintain the environmental profile of agriculture. This is especially true with respect to the most intensive types of farming. From this perspective, the examination of individual farm practices through IOA deserves further consideration as a possible tool to asses (and potentially raise) the environmental performance of farms. In the context of local conditions, the subsequent analysis of accounts may contribute to the establishment of 'standard recommended practice' for groups of accounted farms together with 'individual best practice' for each accounted holding. The former may contribute to delivering a practical meaning to the GAP concept, while the latter provides a potential means of improving the environmental performance of individual farms.

\section{Acknowledgements}

The interest and financial support of DG Agriculture and DG Environment is gratefully acknowledged. Sincere thanks are also given to all the scientists throughout Europe who gave up their time to complete the questionnaires and help with this review. The help of our colleagues $\mathrm{M}$. Hanegraaf, M. Silgram and J. Hermansen in the project is also recognised.

\section{References}

Halberg, N., 1999. Indicators of resource use and environmental impact for use in a decision aid for Danish livestock farmers. Agriculture, Ecosystems and Environment 76, $17-$ 30 . 
Hansen, J., 2000. Nitrogen balances in agriculture. Eurostat report. Statistics in focus. Environment and Energy Theme $8-16 / 2000$.

Langelaan, I., 1997. Stikstofoverschot melkveebedrijven onveranderd [Nitrogen surplus dairy farms unchanged]. In: AgriMonitor LEI-DLO, July 1997. LEI-DLO, The Hague.

Lewis, K.A., Bardon, K.S., 1998. A computer based informal environmental management system for agriculture. Environmental Modelling and Software 13, 123-137.

Noe, E., Halberg, N., 1999. Research experience with tools to involve farmers and local institutions in developing more environment friendly practices. Proceedings of the 64th EAAE-Seminar: Co-operative Strategies to Cope with AgriEnvironmental Problems. Berlin.

O'hlmér, 1998. Models of farmers decision making-problem definition. Swedish Journal of Agricultural Research 28, $17-27$.

Sveinsson, T., Halberg, N., Kristensen, I.S., 1998. Problems associated with nutrient accounting and budgets in mixed farming systems. APMinderhoudhoeve-reeks nr 2. pp. 135140. 